\title{
Transoral Vertebroplasty for Osteolytic C2 Metastasis: Report of 2 Cases
}

\author{
Kyung-Min Kim¹, Joon Ho Yoon', Ji-Woong Kwon², Ho-Shin Gwak \\ ${ }^{1}$ Department of Neurosurgery, Seoul National University College of Medicine, Seoul, \\ ${ }^{2}$ Neuro-oncology Clinic, National Cancer Center, Goyang, \\ ${ }^{3}$ Department of Cancer Control, Graduate School of Cancer Science and Policy, National Cancer Center, Goyang, \\ Republic of Korea
}

Corresponding author:

Ho-Shin Gwak

Department of Cancer Control, Graduate School of Cancer

Science and Policy, National

Cancer Center, 323 Ilsan-ro,

Ilsandong-gu, Goyang 10408,

Republic of Korea

Tel: +82-31-920-1666

Fax: +82-31-920-2798

E-mail: nsghs@ncc.re.kr

Received: March 9, 2018

Revised: November 27, 2018

Accepted: March 21, 2019
Herein we reported 2 cases of vertebroplasty (VP) via the transoral route for osteolytic painful odontoid (C2) metastasis from non-small cell lung cancer. A 52-year-old man, who was diagnosed with non-small cell lung cancer a year ago, presented neck pain, which was aggravated on swallowing in September, 2015. Neuroimaging revealed osteolytic metastasis of C2 with atlanto-axial joint invasion and of $\mathrm{C} 4$ without compression. The metastatic cancer of multiple bone and soft tissues progressed despite the chemotherapy; hence, minimally invasive palliative therapy was needed for immediate relief of the patient's pain. Another patient, 54-year-old man, also diagnosed non-small cell lung cancer revealed neck pain in May, 2018. He had stopped systemic chemotherapy 6 months ago due to lack of effective available regimen and received stereotactic radiosurgery for multiple brain metastases 3 months ago. Spinal computed tomography revealed C2 osteolytic lesion and we performed transoral VP for pain control. Based on our experience, transoral VP for C2 osteolytic metastasis could be performed safely and resulted in significant and immediate pain relief.

Key Words: Cervical vertebrae; Metastasis; Osteolysis; Vertebroplasty

\section{INTRODUCTION}

Vertebroplasty (VP) is the most common treatment choice for patients with osteolytic spine bone metastasis to relieve pain and restore stability in metastatic spinal disease ${ }^{2)}$. Usually, VP is performed to treat thoracolumbar vertebral metastatic lesion via the transpedicular route. Multiple randomized and nonrandomized reports have demonstrated its effectiveness ${ }^{2)}$. However, fractures in the cervical spine are relatively rare, and VP has been applied less commonly in the treatment of cervical metastases due to the complex anatomy of the cervical spine $^{7)}$. Percutaneous VP for cervical osteolytic metastases reported as effective but is mainly applied to the mid-cervical lesion. Transoral VP to treat the odontoid (C2) has been described in only a few case reports. We performed VP for 2 patients with osteolytic C2 metastatic lesion via transoral route under general anesthesia without any complications.

\section{CASE REPORT}

A 52-year-old man was diagnosed with non-small cell lung cancer in February, 2014. Staging work-up revealed no metastatic lesion. However, the mass lesion of lung had already invaded regional lymph nodes and caused endotracheal narrowing; hence, pneumonectomy was deferred. The patient was treated with concurrent chemo-radiation therapy with erlotinib (Tarceva) after confirmation of epidermal growth factor receptor (EGFR) mutation. Despite partial remission at the 6-months follow-up imaging, the 15-months follow-up revealed that the lung cancer had progressed to the whole body (both adrenal glands, multiple bones and soft-tissue metastases) In September, 2015, the patient felt neck pain that was exacerbated on swallowing and neck motion. Computed tomography (CT) scan of the cervical spine demonstrated osteolytic lesion involving the $\mathrm{C} 2$ and $\mathrm{C} 4$ vertebral bodies (Fig. 1A). As the patient pain was not tolerable despite of opioid analgesia and Philadelphia brace, we decided to treat this lesion with more stabilizing method. And, pre-operative magnetic resonance imaging showed paravertebral invasion of metastatic lesion with diffuse posterior wall invasion (Fig. 1B), we could assume that painful swallowing possibly came from his osteolytic metastasis violate the C4 cortex to invade posterior pharyngeal wall, which moved along with glottis on swallowing (Fig. 1B). Considering patients' disseminated cancer lesions, we chose percutaneous VP for $\mathrm{C} 4$ metastasis 
and plan to apply VP for C2 lesion via transoral approach. All procedure was conducted under general anesthesia. First, percutaneous VP for C4 lesion was performed routinely with C-arm without difficulty. Subsequently, the Dingman mouth retractor was applied and the posterior pharyngeal wall was washed 3 times with Betadine solution (Fig. 2). Under the C-arm guide, we located C2 osteolytic lesion with spinal needle as uvula for midline guidance. After confirmation of proper needle location, a $13 \mathrm{G}$ VP needle was inserted into the C2 osteolytic cavity and a total of $2.5 \mathrm{cc}$ bone cement was injected with the pusher (Fig. 1B). No leakage was observed and the ope- ration time was approximately 1 hour in total. After the procedure, patients could eat with little difficulty until he expired 1 month later due to pneumonia from endotracheal narrowing of lung cancer progression.

Another patient, 54-year-old man complaints progressive neck pain since 3 months ago. He was diagnosed with nonsmall cell lung cancer with multiple bone metastases in July, 2012. As his lung cancer did not have the EGFR mutation, he had received several times of radiation therapy and 5 times of cytotoxic chemotherapy. As the last radiation treatment, he received fractionated stereotactic radiation therapy for painful

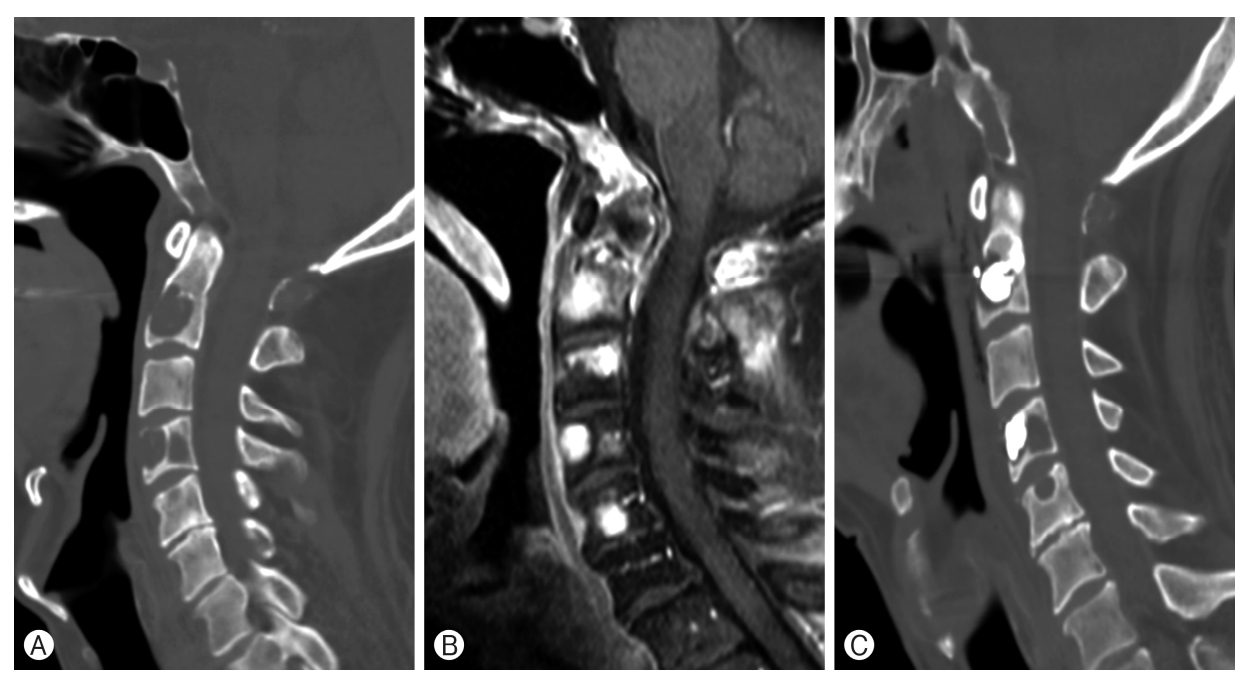

Fig. 1. (A) Pre-operative computed tomography (CT) scan revealed osteolytic metastasis of $C 2$ and C4 vertebral body on sagittal. (B) Pre-operative magnetic resonance imaging with gadolinium enhancement showed multiple cervical spine metastases with posterior pharyngeal wall invasion. (C) Post-operative $\mathrm{CT}$ scan showed bone cement filling the osteolytic gap of cervical vertebrae.

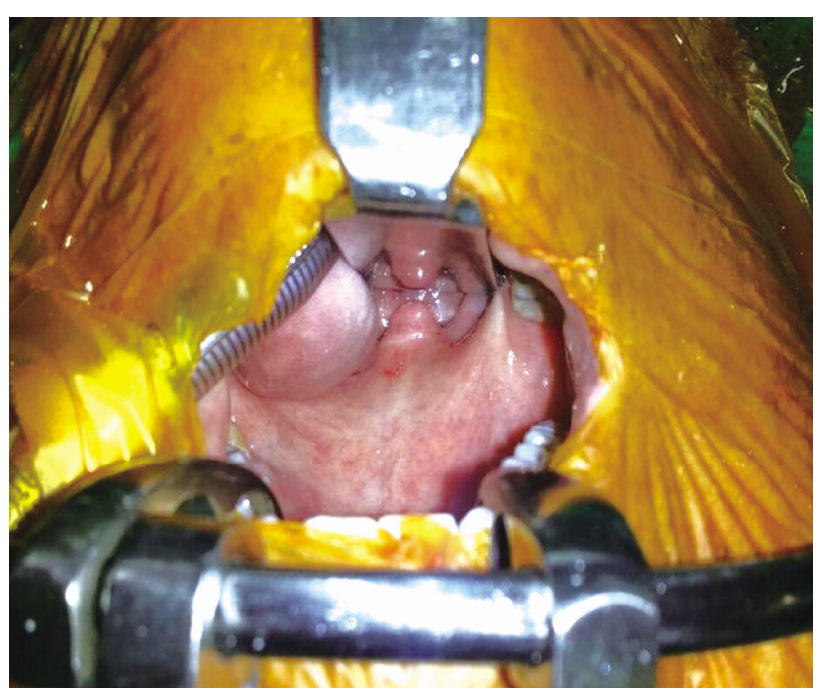

Fig. 2. Dingman mouth retractor is applied to expose posterior pharyngeal wall to insert vertebroplasty needle into C2 vertebral body directly alongside of uvula.

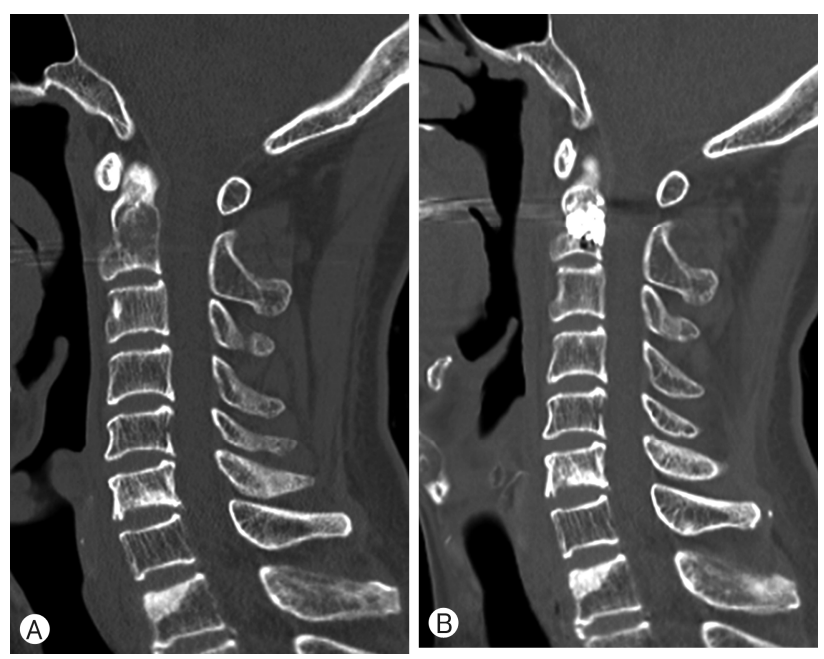

Fig. 3. (A) Pre-operative 3-dimensional (3D) computed tomography (CT) scan revealed osteolytic metastasis of C2 vertebral body, (B) post-operative 3D CT scan showed bone cement filling the osteolytic gap odontoid process. 


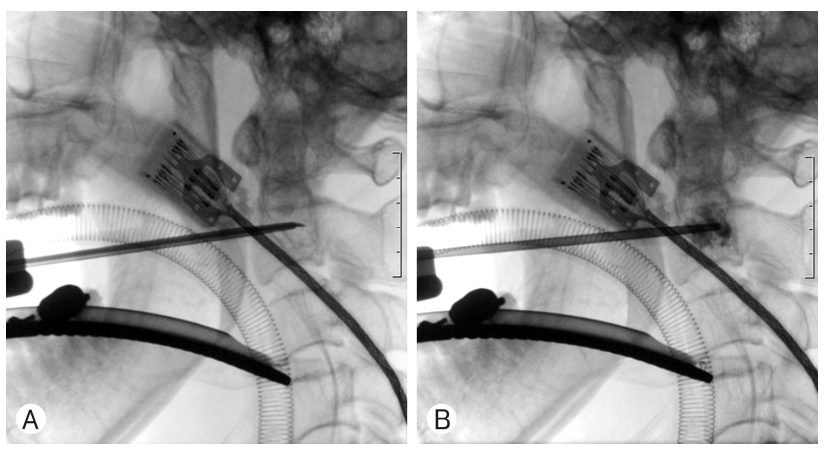

Fig. 4. Fluoroscopic image shows that $13 \mathrm{G}$ vertebroplasty needle was inserted into the $\mathrm{C} 2$ osteolytic cavity (A) and bone cement was injected with the pusher (B).

C2 vertebral metastases 2 months ago (3,200 cGy/4 fraction). However, his neck pain continued, and spinal CT revealed osteolytic lesion of C2 (Fig. 3A). We performed transoral VP as same method. Under the C-arm guide, a $13 \mathrm{G}$ VP needle was inserted into the $\mathrm{C} 2$ osteolytic cavity as uvula for midline and $\mathrm{C} 2$ body locator (Fig. 4A). And a total of $1.9 \mathrm{cc}$ bone cement was injected with the pusher on lateral view (Fig. 4B). After VP, patient neck pain was much improved and post-operative CT revealed filling of osteolytic lesion with bone cement (Fig. 4B).

\section{DISCUSSION}

VP is a widely performed minimally invasive procedure, that is relatively safe and effective in the treatment of osteoporotic and malignancy-related fractures of the thoracolumbar spine $^{2)}$. Recently, in cervical spine lesions, systematic review and meta-analysis revealed that VP for metastatic cervical spine lesion was effective in significant reduction of pain (89\%) with a low risk (4\%) of complications ${ }^{5}$. But VP for the cervical spine is technically difficult and has potential complications due to the complex anatomy around the cervical spine ${ }^{11)}$. Especially, the anterolateral approach used for subaxial cervical VP is risky to apply for $\mathrm{C} 2$ due to possible injuries of many neurovascular structures - including the spinal accessory, lingual, hypoglossal, vagus, marginal, and laryngeal nerves as well as carotid and vertebral arteries ${ }^{1)}$. Anselmetti et al. ${ }^{1)}$ reported the outcome of transoral VP under general anesthesia for 25 patients with C2 malignant involvement like our cases. They achieved immediate pain reduction in $96 \%$ of patients without clinically significant complications. And 96\% of patients had been free from worsening of the pain for 1 year since procedure ${ }^{1)}$. Thus, transoral approach is suggested to be relatively safe method to alternate anterior approach for VP at C2 osteolytic metastases. In other way, Kordecki et al. ${ }^{8)}$ a successful treatment of $\mathrm{C} 2$ metastasis via anterolateral approach. They inserted the needle under local anesthesia with palpation of common carotid artery to avoid at C4-C5 level and advanced superiorly ${ }^{8}$. The advantages of transoral VP could be a more direct needle insertion, and decreased risk to adjacent neurovascular structures ${ }^{1,17)}$.

In the transoral approach, surgical site infection is a major concern because the procedure is performed through the contaminated field. Infection rates for open transoral procedures vary widely from $0.1 \%$ to $13 \% \%^{9,12,16)}$. However, to our best knowledge, no case of surgical site infection related to transoral VP or kyphoplasty has been reported previously ${ }^{1,4,6,10,11,13-15,17)}$. Transoral VP has a lower risk of infection due to minimizing tissue disruption by using the relatively fine needle $e^{1,6,17)}$. The perioperative intravenous antibiotics, antibiotics within the polymethyl methacrylate mixture, and post-procedural antibiotics could further reduce the infection risk ${ }^{1,6,14)}$. We paid particular attention to preparing the surgical field and keeping the needle aseptic during the procedure, and procedure-related infection did not occur in our case.

Several studies indicate that cervical VP has a high technical success rate combined with a low complication rate, while providing immediate pain relief, that lasts for a long-term; in addition, the use of analgesic drugs is reduced ${ }^{1,3,11,13}$. Our patient also showed dramatic pain reduction after the procedure, which continued until he died due to pneumonia aggravation 1 month later.

\section{CONCLUSION}

We could suggest that for painful osteolytic C2 metastasis, transoral VP could be applied as a palliative method to stabilize the vertebra and to improve pain immediately at a little cost of procedure related complication.

\section{CONFLICTS OF INTEREST}

No potential conflict of interest relevant to this article was reported.

\section{REFERENCES}

1. Anselmetti GC, Manca A, Montemurro F, Tutton S, Chiara G, Battistella $M$, et al.: Vertebroplasty using transoral approach in painful malignant involvement of the second cervical vertebra (C2): a single-institution series of 25 patients. Pain Physician 15:35-42, 2012

2. Bae JW, Gwak HS, Kim S, Joo J, Shin SH, Yoo H, et al.: Percutaneous vertebroplasty for patients with metastatic compression fractures of the thoracolumbar spine: clinical and radiological factors affecting functional outcomes. Spine J 16:355-364, 2016

3. Bao L, Jia P, Li J, Chen H, Dong Y, Feng F, et al.: Percutaneous vertebroplasty relieves pain in cervical spine metastases. Pain Res Manag 2017:3926318, 2017

4. Brage L, Roldán H, Plata-Bello J, Martel D, García-Marín V: Transoral vertebroplasty for a C2 aneurysmal bone cyst. Spine J 16:e473-e477, 2016 
5. De la Garza-Ramos R, Benvenutti-Regato M, Caro-Osorio E: Vertebroplasty and kyphoplasty for cervical spine metastases: a systematic review and meta-analysis. Int J Spine Surg 10:7, 2016

6. Kaminsky IA, Härtl R, Sigounas D, Mlot S, Patsalides A: Transoral C2 biopsy and vertebroplasty. Interv Med Appl Sci 5:76-80, 2013

7. Kim SK, Chung JY, Cho CB, Choi HC: Percutaneous anterolateral vertebroplasty for a myelomatous pathologic fracture of the subaxial cervical spine: A case report. Korean J Spine 8:225228, 2011

8. Kordecki K, Lewszuk A, Puławska-Stalmach M, Michalak P, Łukasiewicz A, Sackiewicz I, et al.: Vertebroplasty of cervical vertebra. Pol J Radiol 80:51-56, 2015

9. Laborde G, Gilsbach J, Bertalanffy H, Harders A, Hardenack M: Limits of the transoral approach in craniospinal malformations. Skull Base Surg 2:6-10, 1992

10. Martin JB, Gailloud P, Dietrich PY, Luciani ME, Somon T, Sappino PA, et al.: Direct transoral approach to $\mathrm{C} 2$ for percutaneous vertebroplasty. Cardiovasc Intervent Radiol 25:517519,2002
11. Masala S, Anselmetti GC, Muto M, Mammucari M, Volpi T, Simonetti G: Percutaneous vertebroplasty relieves pain in metastatic cervical fractures. Clin Orthop Relat Res 469:715-722, 2011

12. Menezes AH: Surgical approaches: postoperative care and complications "transoral-transpalatopharyngeal approach to the craniocervical junction”. Childs Nerv Syst 24:1187-1193, 2008

13. Monterumici DA, Narne S, Nena U, Sinigaglia R: Transoral kyphoplasty for tumors in C2. Spine J 7:666-670, 2007

14. Reddy AS, Dinobile D, Orgeta JE, Peri N: Transoral approach to CT-guided C2 interventions. Pain Physician 12:253-258, 2009

15. Sachs DC, Inamasu J, Mendel EE, Guiot BH: Transoral vertebroplasty for renal cell metastasis involving the axis: case report. Spine (Phila Pa 1976) 31:E925-E928, 2006

16. Shousha M, Mosafer A, Boehm H: Infection rate after transoral approach for the upper cervical spine. Spine (Phila Pa 1976) 39:1578-1583, 2014

17. Tong FC, Cloft HJ, Joseph GJ, Rodts GR, Dion JE: Transoral approach to cervical vertebroplasty for multiple myeloma. AJR Am J Roentgenol 175:1322-1324, 2000 